\title{
MOSAICO DA CITRONELA
}

A. S. Costa, engenheiro agrónomo, Seção de Genética, A. R. Lima e A. JAcob, engenheiros agrónomos, Seção de Fumo, Plantas Inseticidas e Medicinais, Instituto Agronômico de Campinas

A cultura da citronela (Cymbopogon winterianus Jowitt) ainda não está estabelecida no Brasil. Estudos sôbre a sua adaptação no Estado de São Paulo e sôbre os métodos mais adequados ao seu cultivo estão em andamento no Instituto Agronômico ( $\left.{ }^{1}\right)$. Observações feitas em pequenas plantações, na Estação Experimental Central em Campinas, mostraram que esta planta é bastante suscetível a uma forma de mosaico. Os sintomas do mosaico da citronela são bastante semelhantes aos do mosaico da cana de açúcar (Saccharum spp.), e as experiências e observações efetuadas indicam que o vírus causador pertence ao grupo do vírus do mosaico da cana (Marmor sacchari $\mathrm{H}$.).

\section{1 - IMPORTÂNCIA ECONÔMICA}

Sendo a citronela planta ainda não cultivada em escala comercial no Estado, a importância econômica atual do mosaico é nula. Esta moléstia é, entretanto, de importância econômica potencial, caso esta cultura venha a implantar-se em São Paulo.

Os prejuízos causados pelo mosaico da citronela são de duas naturezas : $a$ ) as plantas afetadas produzem menor quantidade de fôlhas que as plantas sadias ; $b$ ) observaçס̃es preliminares têm mostrado que a percentagem de óleo de citronela das plantas com mosaico é cêrca de 25 por cento menor que das plantas sadias.

Sendo o mosaico da citronela causado pelo mesmo vírus que origina o mosaico da cana, as plantas de citronela poderãoservir de fonte de vírus para as plantações de cana de açúcar, e vice-versa.

\section{2 - SINTOMAS}

As plantas afetadas de citronela mostram sintomas de mosaico das fôlhas (est. 1- $A$ ). 0 tipo de mosaico é formado por áreas verde-claras alongadas que se alternam com áreas de côr verde normal. $O$ tamanho das plantas não é, em geral, muito reduzido, mas há plantas que permanecem bastante definhadas quando afetadas.

\section{3 - TESTES COMPARATIVOS}

Numerosos ensaios comparativos de inoculação foram feitos com o vírus do mosaico da citronela e do mosaico da cana de açúcar. Os vírus

(1) As poucas mudas com que se inioiou a cultura vieram de Mayaguez, Porto Rico. 
das duas proveniências foram comparados por inoculação em plantinhas de sorgo, em plantas de linhas puras e variedades de milho, e em seedlings de citronela e de cana de açúcar. Os resultados destas inoculações estão reproduzidos no quadro 1 e indicam que o comportamento dos dois vírus foi o mesmo. Também nenhuma diferença foi observada nos sintomas causados pelos dois vírus nas plantas inoculadas.

Quadro 1.-Inoculação comparativa (1) de várias plantas com os vírus do mosaico da citronela e do mosaico da cana de açúcar

\begin{tabular}{|c|c|c|c|c|c|c|}
\hline \multirow{3}{*}{ Planta inoculada } & \multicolumn{3}{|c|}{ Vírus do mosaico da citronela } & \multicolumn{3}{|c|}{ Vírua do mosaico da cana de açúcar } \\
\hline & \multicolumn{2}{|c|}{ Plantas } & \multirow{2}{*}{$\begin{array}{l}\text { Percen- } \\
\text { tagem de } \\
\text { infeçãa }\end{array}$} & \multicolumn{2}{|c|}{ Plantas } & \multirow{2}{*}{$\begin{array}{l}\text { Percen- } \\
\text { tagem de } \\
\text { infecção }\end{array}$} \\
\hline & $\begin{array}{l}\text { Inoeu- } \\
\text { ladas }\end{array}$ & $\begin{array}{l}\text { Infe- } \\
\text { tadas }\end{array}$ & & $\begin{array}{l}\text { Inoou- } \\
\text { ladas }\end{array}$ & $\begin{array}{l}\text { Infe- } \\
\text { tadas }\end{array}$ & \\
\hline & $N .^{\circ}$ & $N . \circ$ & $\%$ & $N .{ }^{\circ}$ & $N .0^{\circ}$ & $\%$ \\
\hline Sorgo $\left({ }^{2}\right)$ & 98 & 16 & 16,3 & 91 & 33 & 35,1 \\
\hline Linhas puras de milho $\left({ }^{3}\right)$ & 248 & 75 & 30,2 & 248 & 135 & 54,4 \\
\hline Variedades de milho $\left({ }^{4}\right)$ & 1100 & 970 & 88,2 & 1100 & 998 & 90,7 \\
\hline Seedlings de citronela ............... & 218 & 218 & 100 & 218 & 218 & 100 \\
\hline Seedlings de crna de açúcar ..... & 380 & 193 & 50,7 & 380 & 192 & 50,5 \\
\hline
\end{tabular}

(1) Inbculo diluído 1:5 com sulfito de sodio a $0,01 \mathrm{M}$

(2) Totais de 10 variedades

(3) Totais de 31 linhas puras

(4) Totais de 110 variedades

Em outra série de ensaios compararam-se as propriedades físicas do vírus causador do mosaico da citronela com aquelas do vírus do mosaico da cana de açúcar. Os testes foram feitos por inoculação mecânica de plantinhas novas de milho (1), e os resultados estão reproduzidos no quadro 2.

QUADRo 2.--Resultados dos testes comparativos para determinação das propriedades físicas do vírus do mosaico da citronela e do mosaico da cana de açúcar, efetuados com planta de milho

\begin{tabular}{|c|c|c|c|c|c|c|c|c|}
\hline \multicolumn{3}{|c|}{ Resistencia a diluição } & \multicolumn{3}{|c|}{ Inativação termal } & \multicolumn{3}{|c|}{ Envelhecimento in vitro } \\
\hline \multirow{2}{*}{$\begin{array}{l}\text { Diluiçāo do } \\
\text { intculo }\end{array}$} & \multicolumn{2}{|c|}{$\begin{array}{l}\text { Plantas infetadas, } \\
\text { de } 15 \text { inoculadas } \\
\text { com o vírus da }\end{array}$} & \multirow{2}{*}{$\begin{array}{l}\text { Tempe- } \\
\text { ratura } \\
\text { em oC }\end{array}$} & \multicolumn{2}{|c|}{$\begin{array}{l}\text { Plantas infetadas, } \\
\text { de } 30 \text { inoculadas } \\
\text { rom o virus da }\end{array}$} & \multirow{2}{*}{$\begin{array}{l}\text { Periodo } \\
\text { de enve- } \\
\text { lheci- } \\
\text { mento } \\
\text { em horas }\end{array}$} & \multicolumn{2}{|c|}{$\begin{array}{l}\text { Plantas infetadas, } \\
\text { de } 30 \text { inoculadas } \\
\text { com o virus da }\end{array}$} \\
\hline & $\begin{array}{l}\text { Citro- } \\
\text { nela }\end{array}$ & $\begin{array}{l}\text { Cana de } \\
\text { açúcar }\end{array}$ & & $\begin{array}{l}\text { Citro- } \\
\text { nela }\end{array}$ & $\begin{array}{c}\text { Cana de } \\
\text { açúcar }\end{array}$ & & $\begin{array}{l}\text { Citro- } \\
\text { nela. }\end{array}$ & $\begin{array}{l}\text { Cana de } \\
\text { acúcar }\end{array}$ \\
\hline & $N . \circ$ & $N .0$ & & $N .0^{\circ}$ & $N .{ }^{\circ}$ & & $N . .^{\circ}$ & $N .{ }^{\circ}$ \\
\hline Não diluido. & 15 & 15 & N/aquec. & 30 & 30 & $0 \ldots$ & 13 & 19 \\
\hline $10^{-2}$ & 11 & 11 & $50 . \ldots$ & 6 & 5 & 7. ... & 2 & 19 \\
\hline $10^{-3}$ & 2 & 5 & $55 \ldots$ & $\mathbf{0}$ & I & $9 . \ldots$ & 1 & 13 \\
\hline $10^{-4}$ & $\mathbf{0}$ & 1 & $60 . \ldots$ & 0 & 0 & $24 \ldots \ldots$ & 0 & 6 \\
\hline $10^{-5}$ & 0 & 1 & 65 & 0 & 0 & $48 \ldots \ldots$ & 0 & 0 \\
\hline
\end{tabular}



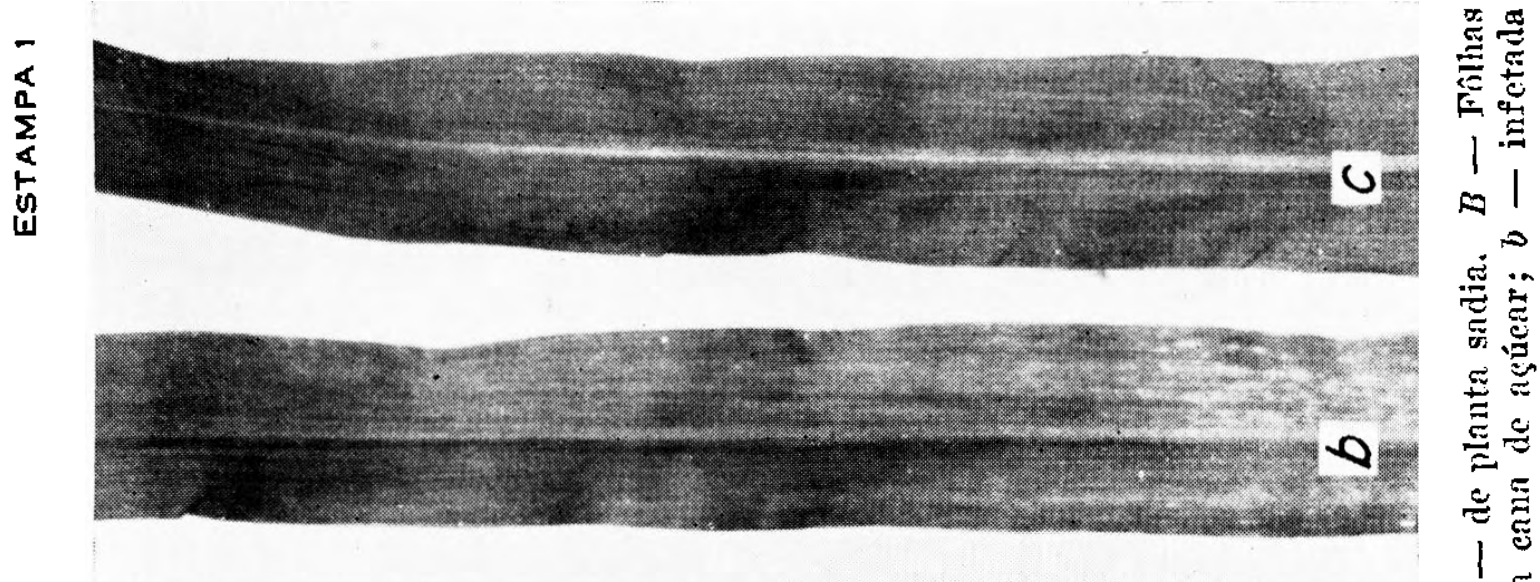

焉

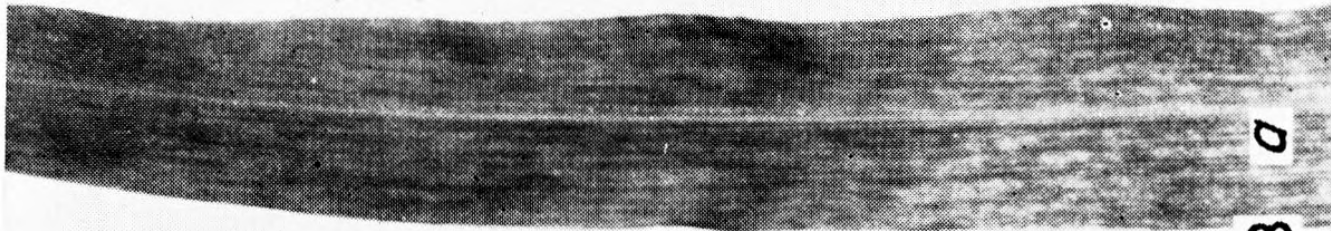

0 穷

08

를

突

号

미

옹

吅

至密㤩
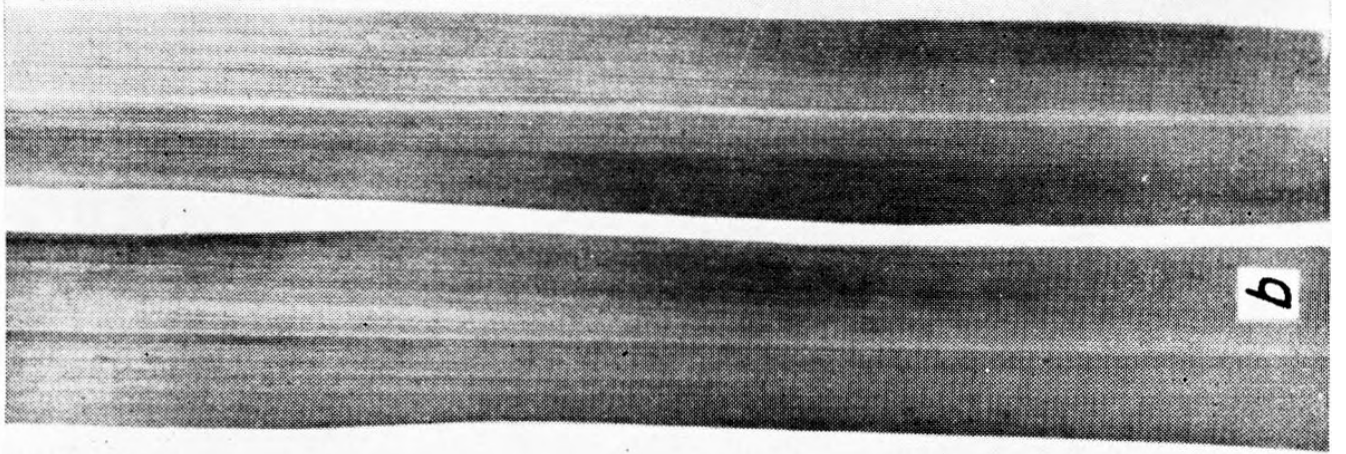

胥

号

당

至突。

焉

$=4$

禺

11 章

$\theta$

a

옳욜
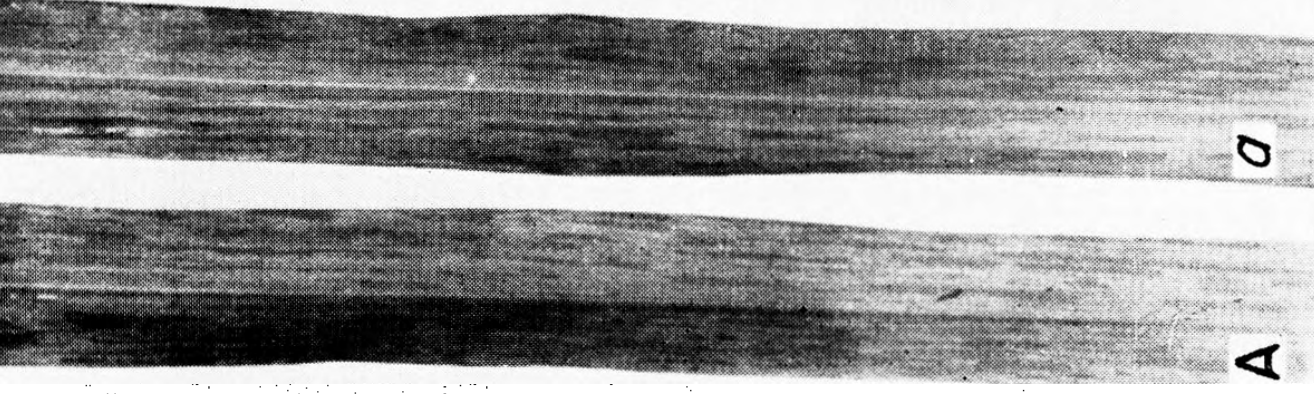
Pode-se afirmar, de maneira geral, que as propriedades físicas dos dois vírus não diferem significantemente. Há pequena indicação de que o inóculo obtido de plantas de cana de açúcar é um pouco mais ativo do que aquêle obtido de citronela. Foi também verificado que o vírus presente em suco obtido de fôlhas de cana de açúcar infetadas pelo mosaico permaneceu ativo in vitro por mais tempo do que o vírus obtido de fôlhas de citronela.

\section{4 - TRANSMISSÃO DO MOSAICO DA CITRONELA}

Nos ensaios efetuados, o vírus causador do mosaico da citronela tem sido transmitido por inoculação mecânica. Notou-se que os seedlings de citronela são muito mais fàcilmente infetados pelo mosaico do que os seedlings de cana de açúcar. Isto se verificou tanto quando o inóculo era proveniente de citronela como da cana de açúcar.

Ainda não foram determinados quais são os insetos vetores responsáveis pela transmissão do mosaico sob condições naturais em plantações de citronela. É de se presumir que seja transmitido pelos mesmos vetores do mosaico da cana de açúcar. Falta também determinar se os casos de infecção de plantas de citronela resultam de vetores virulíferos provenientes de plantações de cana ou se há também disseminação de citronela para citronela.

\section{5 - CONTRÔLE}

Há várias medidas que podem ser postas em prática com a finalidade de controlar o mosaico da citronela : a) contrôle por isolamento das plantações e arrancamento das plantas afetadas; $b$ ) criação de variedades resistentes ; c) seleção de variedades ou clones tolerantes ; d) multiplicação de clones invadidos por estirpes fracas do vírus causador do mosaico.

$O$ isolamento e arrancamento das plantas afetadas (roguing) é mais indicado para o caso de plantações destinadas ao fornecimento de mudas. Nesse caso seria conveniente que a plantação fôsse feita em local isolado, longe de outras plantações de citronela ou de cana. Periòdicamente, as plantas deveriam ser inspecionadas, praticando-se o arrancamento e destruição de tôdas que se apresentassem afetadas pelo mosaico, como é praticado, com bons resultados, para a cana de açúcar (2).

O problema da seleção de variedades ou clones resistentes não parece bastante promissor, principalmente a partir de material genético existente em São Paulo. Nos testes de inoculação efetuados com mudinhas obtidas a partir de sementes têm sido obtidos 100 por cento de infecção, indicando isto que não existem fatôres para resistência no material que foi introduzido. Guenther (3) refere-se a duas espécies de citronela, Cymbopogon winterianus e $C$. nardus Rendle. C. winterianus é a mais cultivada em Java e produz óleo de melhor qualidade. $\hat{\mathrm{E}}$, entretanto, mais exigente quanto ao solo, sendo, aparentemente, planta menos rústica. $C$. nardus é mais cultivada no Ceilão, dá óleo de qualidade algo inferior, mas é planta 
mais rústica. A introdução de outras variedades destas duas espécies é aconselhável, pois é possível que o material introduzido anteriormente em São Paulo represente apenas um clone, não podendo oferecer a variabilidade genética necessária para melhoramento.

É possível que o estudo de seedlings de citronela infetados pelo mosaico venha mostrar que alguns são mais tolerantes à moléstia que outros. Caso essa tolerância seja bastante grande, tornar-se-á possivel a obtenção de clones que, embora afetados pelo mosaico, sejam capazes de produzir satisfatòriamente.

Outra possibilidade digna de estudos seria a da introdução de estirpes fracas do vírus do mosaico em clones de citronela, a fim de verificar se as plantas invadidas ficam protegidas contra a invasão por estirpes causadoras de sintomas mais severos.

\section{S U M M A R Y}

A type of mosaic is commonly found in experimental fields of the citronella plant (Cymbopogon winterianus) in the State of São Paulo.

Inoculation tests carried out with the viruses of citronella and sugar cane mosaic showed that the symptoms induced by both viruses on a number of host plants were alike. The results of these tests and those obtained in a comparative study of some properties of the two viruses indicated that the citronella mosaic virus belongs to the sugar cane mosaic virus complex.

\section{LITERATURA CITADA}

1. Arruda, Spencer, C. As doenças da cana de açúcar no Estado de São Paulo IV. O Biológico 12 : 123-124. 1946.

2. Costa, A. S. e M. P. Penteado. O milho como planta-teste para o vírus do mosaico da cana de açúcar. Bragantia 10 : 93-94. 1950.

3. Guenther, Ernest. Em The essential oils. D. Van Nostrand, Inc. Nova York. $4: 67.1950$. 